\title{
Geração do bandeirismo humanista *
}

\author{
Raphael Valentino Sobrinho
}

\section{Significação da formatura e o convívio acadêmico}

Ei-nos no ponto zenital da vida acadêmica, na hora tantas vêzes idealizada, para onde convergiram, rescendendo a fragrância do entusiasmo, os sacrifícios e as elucubrações cotidianas, os devaneios e os embates peculiares a êste ciclo indelével da nossa formação intelectual.

Durante um lustro, construimos com apuro, a cada átomo, o presente minuto pinacular, esmaltado, cinco anos atrás, pelas réstias da esperança, dourado hoje, pela taumaturgia da saudade, numa transmigração eviterna da alma para a riqueza polimorfa dos estados vividos ou sonhados.

Mescla-se, assim, a magnificência dos planos triunfantes como ocaso do dileto convívio universitário, bruxoleando, agora, ao flamejar de um porvir incerto.

À guisa dos sons, encadeados em êxtase sobrenatural nos arroubos dos artistas, os homens se acrisolam e elevam através do prodígio da reciprocidade. A intuição do significado relevante dêste fenômeno levou Pitágoras a escolher para base do real, no seu sistema, o número e a harmonia. Com o auxílio desta, suprem os virtuosos as lacunas da palavra, corporificando os sentimentos inefáveis e encontram as individualidades desgarradas a forma

* Discurso proferido pelo bacharelando Raphael Valentino Sobrinho, orador da turma de 1958 da Faculdade de Direito da Universidade de São Paulo, na solenidade de colação de grau realizada no dia 10 de abril de 1959 . 
supina da anulação do oposto e do inerte; reconhecem-se, então, as consciências e o sair de si mesmo é, no fundo, um reencontrar-se, depois de ampliar as possibilidades do outro e de adquirir novas e fecundas dimensões. Ao esplendor dos valores coletivos, cada qual se transcendentaliza na alma comum, porque radica nas profundezas do ser os ideais que unem os anelos e solidificam as comunidades concretas.

Fascinantes são tôdas as lídimas formas de comunicação humana; rutilam, porém, com mais intenso fulgor as colmeias de inteligências no desabrochar, pois a mocidade, como o perene milagre do arrebol, se compõe de "um vestígio de sonho e de um princípio de pensamento". Quem contempla a apinhada adolescência jônica -- proclamavam os hinos homéricos - crê que jamais ela envelhecerá, porque da sua ação e arrebatamento dimanaram a arte e a filosofia, a curiosidade da pesquisa e principalmente a fé no valor da pessoa.

Os ideais da juventude, dando-se a mão por cima dos séculos, zombam da pujança dos impérios, mofam do pragmatismo caricato dos poderosos, porque viceja no seu âmago o segrêdo da eternidade, a demonstrar para todo sempre que o homem só se dignifica, aninhando-se nos esplendores trágicos da idéia. Adejar para as cogitações transformadoras do mundo é algo que participa da insensatez do furor mas se reveste do encanto excelso do heroismo.

A decomposição social da nossa época é fruto da "ausência de mocidade"; imolaram-na as gerações pré-bélicas em holocausto às grandes potências, mal a conhece o após-guerra, flagelado por uma nova barbárie, que proscreve o ideal em nome da mediocridade, apedreja os heróis na apologia da tibieza e santifica o conformismo, aceitando o cativeiro.

Eis porque, ao inserir-nos na radiosa família acadêmica, ainda neófitos tímidos, nos cativou a sua indole estética, a apontar sem tréguas novos rumos valorativos em 
contraposição às formas declinantes do existir. Nas meditações das manhãs de estudo, no ardor das noites festivas e das pugnas políticas, surdia a beleza marcante do espírito comunitário, trazendo consigo a promessa suprema de vencer a nostalgia da solidão.

Aqui, há quase uma centúria e meia, entre as paredes de taipa do velho Convento de São Francisco, homiziaramse o amor à Justiça e o sentimento da beleza. O Direito - como proporção e medida da convivência —, a Poesia como intérprete da realidade no que ela tem de humano e sensível — enlevaram-se nas primícias de um amplexo, cujos albores lhe pressagiaram a infinitude, jurando perpétua e mútua fidelidade. Desde então, os mesmos anseios e as mesmas aflições se espelharam nos olhos de ambos; os lauréis da palavra melódica ataviaram o gládio do Direito e as duas realezas, sem corar, luziram na pugna comum pela hegemonia da Justiça. As abelhas doiradas da juventude fretiniram, saudando a maravilha dêsse enlace; o coração brônzeo de Têmis partiu-se para receber o impulso do humanismo e o aviário canoro das Arcadas principiou a ressoar em nome das grandes causas.

Em todos os grupos, inclusive nos centros universitários, introduzem-se espíritos impermeáveis às centelhas transpessoais e opõem-se à institucionalização do corpo social, porque lhe desnaturam o sentido integrativo; encerrados no ergástulo da própria apatia ou de estulta vaidade, ensurdecem tais elementos aos apelos das presenças circundantes. Oxalá o predomínio da apatia nunca se concretize nesta Casa, anunciando a curva da senectude, a austeridade hierática, indiferente e semi-morta, incapaz de absorver os mais úberes legados espirituais.

A existência é o cenário constante das despedidas confessou o gênio da música romântica na sutilidade emocional do "lento", dedicado ao idílio segundo seu coração, sua raça e sua fé. Sente o homem a crueza desta verdade, com todo o travor, quando, no imenso disco do passado, se afogam as imagens caras $\mathrm{e}$ as vivências sublimes. A 
magnitude do nosso destino, emergente da sintese do dever e da vocação, não permite, todavia, nos desfaçamos em caramunhas, ao apartar-nos do aconchêgo de uma comunidade.

Reponta, destarte, na cerimônia de hoje, antes uma diretriz para o porvir que uma recordação melancólica e infrutífera do pretérito. Viver é sentir-se projetado para o futuro, plasmando-o com os meios fornecidos pelo arsenal imutável dos tempos transatos. Consolida-se, pois, neste instante, um vínculo a envolver a totalidade do nosso ser, porque representa a condição para alcançarmos o eu autêntico e propelir, cada vez mais conscientemente o nosso eu infra-existencial, até atingir os píncaros de um devotamento verdadeiro.

Juramos fidelidade à Justiça, virtude perfeita, no dizer do mestre de Estagira, estrêla formada na nebulosa dos nossos instintos e da nossa vida incompreensivel, por ser igualmente a bondade e a piedade, a generosidade e o egoismo. Dedicamo-nos, doravante, ao enobrecimento da conduta nos seus laços intersubjetivos, congregando-nos em tôrno de um bem que é o querer necessário e o fundamento racional do desejo de reciprocidade.

Malfadada seria a missão histórica das Arcadas se elas não se engastassem na órbita das fôrças modeladoras das várias épocas, imprimindo-lhes a nobreza da sua altitude vital. Por êsse motivo, a Academia infunde nos corações de seus filhos o afã inesgotável de renovação na constância da liberdade e o vigor necessário para não macularem com a perfídia o juramento proferido no dia solene da formatura.

Ao filosofarmos sôbre a História da Faculdade de Direito, duas notas rebrilham de imediato: a primazia e a liberdade do espírito e a inquietude ante o fato cumprido. A sua cosmovisão, por natureza, não é "cumulativa", porque não pode cultuar apenas o que foi. $O$ poeta já ressaltou com acêrto: o seu tradicionalismo não é uma fôlha esquecida, mas é uma "fôlha dobrada", que se volta 
a ler e a escrever, pois a Academia do presente deve agigantar a do passado, deve ser a Academia da humanização do progresso e do Direito, a Academia de uma nova Campanha Civilista, a Academia do idealismo levitando nos horizontes históricos, a matizar a obra ininterrupta de um povo, cuja alma agasalhou a apoteose da mocidade.

\section{A mocidade e o renascer do humanismo}

Coincide o raiar da nossa vida profissional com o declínio inquietante de uma cultura, crestada pela angústia do estertor. Transpomos o século das ansiedades intensas e das perplexões múltiplas, porque a mais árdua das tarefas se nos impõe: querer sem esperança imediata.

Assinala o período coevo da evolução humana o "fim do eterno" na inteligência e na emotividade, como demonstrou Julien Benda. Indubitàvelmente, a aptidão para ascender do caso concreto à categoria, de abstrair formulando princípios genéricos extrema o civilizado do bárbaro, o pensamento adulto do infantil. Já não se, crê, entretanto, em valôres imperecíveis nem em regras gerais. Cada segundo, na temporalidade, possui as suas leis, desconexas de tôdas as outras. $O$ acaso erige-se como legislador supremo da conduta, insensivel aos eflúvios de qualquer verdade.

Entre a "moral comodista" das elites em decadência, infensa aos halos revitalizantes e a "vida perigosa" exaltada por Nietzche, há um reino reservado à soberania da cultura. Nas suas coordenadas não se canoniza o frenesi do aventureiro nem se agrilhoa o bandeirismo - sentimento insuprimivel da faculdade inventiva, construtora e renovadora do homem.

Os arcanos da natureza desvendam-se num triunfo do saber; a técnica submete a quase integralidade dos fenômenos físicos aos seus comandos, enquanto uma consciência comum negativa caracteriza a paisagem pròpriamente 
humana do mundo hodierno. O temor alternando com a indiferença recebe o atributo de ideologia dominante, para prenunciar os paroxismos de uma civilização a-finalista, sem o programa último do devido e do indevido, do possível e do impossível.

O entusiasmo pela inteligência, surdindo do fascínio da filosofia cartesiana, do sistema barroco de Leibnitz esboroou-se no limiar do século $\mathrm{XX}$, quando tremeluziu nova deusa: a vontade. $O$ intelectualismo encontrou, então, na sua ruina a penitência do desmedido orgulho, pois o pensamento não é a realidade única e primária; é, ao invés, uma reação a que a vida nos constrange, porque deita raizes no fato prévio e terrível de viver. Entretecendo-se apenas em "idéias de idéias" - segundo a expressão de Ortega - a cultura tornou-se incapaz de nortear os destinos humanos, perdeu-se nos arabescos de interminável dialética. Só idéias de sentimentos, de normas, de emprêsas e de deuses podem provocar revoluções inauditas e metamorfoses essenciais.

Pairando solitária nos fastos da era contemporânea, a vontade gerou o portento de uma civilização material; tortura-a, porém, a ausência de um rumo definido. Habituou-se a humanidade ao furor dos combates e à obstinação das resistências: esvaindo-se, contudo, a quimera do consenso puramente científico e a da tecnocracia, nenhum outro valor subordinante, nenhuma outra idéia-fôrça irrompeu para substituir as "estruturas de vigência" empanadas. Os homens ora se isolam, ora se aglomeram em ajuntamentos sem unidade, na vã tentativa de encontrar entre as multidões o que não existe em cada um. Faltalhes, enfim. uma diretriz, uma estrêla polar valorativa para imantar-lhes as ações e colori-las de humanismo.

O espetáculo agônico da cultura - inimpressionável às imposições do contôrno - enseja o aparecimento da violência e da magia fantasista.

Pasma, sobremaneira, na atualidade, a expansão da fôrça arbitrária - elemento adiáforo e inconsistente - 
cujos clarôes têm a efemeridade dos ribombos que a acompanham, sem imprimir no recesso das consciências o sulco de um ideal ou o calor de uma convicção. Os mais relevantes problemas se resolvem pelas armas, porque a cultura e o Direito só atuam após o seu esfuziar, emprestando aspecto jurídico e humanitário aos fatos consumados. A grandeza dos exércitos repousa, todavia, na sua humildade perante a Justiça e os imperativos do pensamento. Ruy já o dissera: "a Nação governa; o exército, como os demais órgãos do país, obedece". Apesar do ciclópico desenvolvimento da indústria em nossa éra, é inevitável reconheçamos certa margem de barbarismo; nos momentos de incerteza nacional e internacional, a palavra derradeira cabe ao rugir dos canhões, devido ao desprestígio inominável da "razão vital" e ao malôgro do poder diretivo das idéias. $O$ bulício guerreiro não se agita, contudo, em favor de projetos comunitários; estruge impelido pelas paixões movediças e egoistas dos seus propulsores.

Ao lado da violência, medra a magia legendária. Falaciosos salvadores, por meio de processos de sugestionamento coletivo, galvanizam a sensibilidade das massas, com o fito de monopolizar o poder. Tremulam as civilizações entre os galarins e o poente dos líderes carismáticos; as tendências anti-históricas da política rompem qualquer contacto com o passado, reputando-o funesto manancial a nutrir a independência dos homens. Substıtui-se, então, o conhecimento autêntico da evolução social por falsas e miraculosas fórmulas, nimbadas pelo velo da lenda.

A utopia da nova idade áurea. envolta ainda no apocalipse do futuro, pretende justificar o vexame oas gerações atuais, num doloroso esfôrço de parturição. Mártires anônimos perecem na ara imaginária de uma socieđade perteita, onde não haveria ódios nem competições, concretizando-se o infinito das leis ético-sociais. Os adeptos de tal miragem instituem como princípio capital do seu sistema a destruicão. Só dos escombros, só do exício guindado a técnica salvadora poderá aflorar o "éden terrestre". 
E o homem - inequívoco fim da Politica e do Direito, como salienta Kant - converte-se em instrumento de nefasta experiência que visa estruturar comunidades irrealizáveis. A pessoa passa a representar simples potência passiva, esquema abstrato de sujeição; nenhum destino autônomo se lhe assegura, além do colimado pelos grupos dominantes.

Voltando-nos do cenário dos fatos para o das ideologias, encontramos um mundo fracionado entre duas visões unilaterais. Separa-as o calidoscópio dos preconceitos e dos interêsses imediatos antes que as urgências vitais e a autenticidade dos seus fatôres estimativos. Aos que concebem o bem comum como equilíbrio automático dos egoismos, como pasto indefeso das ambições individuais opõemse os transpersonalistas, partidários da preponderância absoluta do todo, através de flexível dirigismo. Uns e outros deformam a realidade; o homem não é só indivíduo mas também não é só social. Somos sêres bivalentes — na expressão de insigne jusfilósofo contemporâneo - porque, de algum modo, somos nós mesmos e também os outros.

Atente-se para o despertar e o evolver das consciências e invalidando a unilateralidade de ambas as perspectivas, emergem, de pronto, as dimensões daquelas: a vocação, a encarnação do ideal e a aspiração comunitária. Meditando sôbre a miríade de apelos que incidem e se refrangem no imenso cristal da vida humana, sentimo-nos atraidos pelo mistério de algumas dessas mensagens multicores que o nosso espírito capta: é o toque altívago da vocação. Desde aí, a forma de existência eleita é uma divindade que em nós se encarna e burila nas grimpas do nosso ser a trajetória, por vêzes dolente, da sua realização. Mas os esboços isolados dos indivíduos se esvanecem antes de se corporizar; por isso o ardor vocacional determina a exigência associativa. Entreabre-se, a todo instante, o nosso ser para o diálogo fecundo com a sociedade e enriquecendo-a com a nossa vivência valorativa, percebemos que ela também nos engrandece em virtude da comunhão entre seus membros. 
Perde, pois, significado a contenda entre as duas visões parciais: a individualista e a transpersonalista. Uma convergência de ambas as perspectivas sob a égide do humanismo é o que reclamam os povos. Nem é lícito, ao Estado entoar, de braços cruzados, hinos à liberdade nem lhe é licito, outrossim, sufocar a eminência supina do homem, que consiste em ser agente da História, introduzindo-lhe no processo valôres novos, graças à sua participação nas esferas do real e do ideal.

A era em que nos situamos define o conteúdo da nossa responsabilidade: devemos constituir a geração do bandeirismo humanista, subordinando as conquistas técnico-científicas e o progresso político-jurídico aos legítimos fins da pessoa, vista como encruzilhada tangencial da matéria e do espírito.

Ao humanismo estético, intelectual e diletante de outrora suceda o humanismo ativo, compreendido como preservação do que o mundo já conheceu de melhor e como ansiedade insopitável de ampliar os álveos da vida, num transcender inerente à nossa espécie.

Imaginou-se, aos primieros impactos das possibilidades da técnica, transferir para o seu domínio a solução de todos os problemas existenciais; arvorou-se o sentido nihilista da neutralidade dos fins em regra determinante do agir. Sem tardança, porém, adveio o desalento - sequela fatal dessa fantasmagoria. Temem-se as bombas e os teleguiados como se representassem algum perigo, de per si, e não constituissem sintomas da corrupção da ética pela vontade de poder. Ignorando a subjetividade - indiscutível dado científico - chega-se, enfim, à alienação humana, fenômeno que a Filosofia do nosso século acentuou com raro êxito. Com efeito, atribuir à racionalização dos instrumentos técnicos o govêrno do universo é renúncia abjecta do homem ao seu pôsto no cosmos.

Ao renascer o espírito humanista - genuino cerne da cultura ocidental - a divisão do trabalho não equivalerá ao divórcio das tarefas sociais nem à indiferença de um 
grupo ante os outros, gerando a exclusão recíproca das várias classes; o sentimento de posse não continuará monopolizando a existência interior mediante falsa primazia; o Estado não poderá apresentar-se ao cidadão como presença indesejável, como simples cobrador de taxas e impositor de serviços, porque a sua problemática não há de se exaurir na glosa da antítese contratualista entre individuo e sociedade, refletindo, ao contrário, a procura de um estatuto de integração social; a democracia, por fim, não será mera tutela de uma liberdade negativa, destituida de objetivos, porque há de exalçar entre os seus escopos a orientacão e o incremento dessa liberdade. segundo os projetos comunitários.

Ceda a liberdade ilusória à verdadeira, aceitando, de modo espontâneo os próprios limites; transfira-se o "ethos" político da sociedade livre para o orbe econômico, através de uma ética de cooperação.

O govêrno só se confie a quem tiver encarnado um ideal de aperfeiçoamento conıum! Basta de líderes carismáticos! Basta de caudilhus! O poder emana do povo, mas acima dêste sobreleve se uma cultura que o resguarde e ilumine, capaz não apenas de dominar a natureza mas também de aprimorar as subjetividades criadoras.

Não se transforme a vontade do Estado - método para exprimir os direitos das fôrças sociais - em principio "per se stante", em propriedade de algumas classes, com detrimento das demais. Realize-se, assim, o magnífico desiderato de Max Scheler: "que a aristocracia no céu não destrua a democracia na terra"

Retumbe a ardência da mocidade, estrujam os centros universitários na cruzada do "bandeirismo humanista". lançando uma ponte entre a imagem físico-matemática do universo e a sua compreensão histórico-cultural. Submeta-se a técnica e a política ao primado do humano. No cumprimento dessa missão que a História nos outorga. relembremos o sublime imperativo kantiano: 
"Atuai como se o princípio da vossa ação devesse, por vossa vontade, converter-se em lei geral".

\section{O direito e a nova aurora humanista}

Instrumento da vida humana, enlaça-se a Jurisprudência na crise que a subjuga. As suas prístinas categorias, revigoradas no primeiro instituto de cultura superior, na vetusta Bolonha de Irnerius, embatem-se contra a insubmissão da coetânea idade dionisiaca. Os fatos sociais rompem crebramente os limites inflexíveis da legalidade; os parlamentos legiferam enquanto as massas se subvertem e a rajada da descrença no Direito transfixa muitas inteligências.

O império da norma revela, por si mesmo, o predomínio da mais alta espiritualidade, por ser o reflexo do pendor para o convívio social e do consequente repúdio ao isolamento egoista, implicando. outrossim, preferência por um perímetro sistemático de juizos e atos, em oposição à volubilidade do poder arbitrário e desenfreado. $\mathrm{O}$ homem é homem em virtude da norma - assegura José Juan Bruera - pois o seu prevalecimento envolve incomensurável confiança na solidariedade social.

A vocação jurídica impõe um tipo complexo de vida. O inesquecível Pontífice Pio XII, autor do significativo lema "Opus Justitiæ Pax", em síntese lapidar, exaltou a figura do jurista: "criatura que se agita entre o finito e o infinito, num movimento necessário que exprime tôda a nobreza da ciência por êle cultivada; se o objeto das suas indagações são as normas, o sujeito a que se destinam é o homem, não em sua parte inferior e menos nobre.. mas o homem na sua parte superior, na sua propriedade específica de agente racional. ."

Intenta-se, sobretudo nos dias contemporâneos, depurar de maneira completa o Direito; reduz-se, então, o jurista ao calculador de conceitos - segundo a crítica mordaz de Savigny - equacionando abstrações e ritmando 
intrincadas formalidades, de que os povos podem prescindir tranquilamente.

No genuino cultor da Jurisprudência entremeiam-se as preocupações do "homem teorético", os zelos do político, do "homem social" e os arrebatamentos dos estetas; ante os seus olhos, perpassam tôdas as fôrças vitais, na agrura das pugnas e no frêmito ascensional. O Direito e o Estado, perdidos no formalismo, desvinculados das exigências humanas transfundem-se em aparatos de opressão da pessoa ou em fatôres de liberdade anárquica.

Animar a Ciência Jurídica apenas com a Lógica é condená-la à miséria. Êste, aliás, é o seu drama presente, visto que, perdendo-se no nominalismo das categorias conceituais e nas especiosidades de uma técnica sem objetivos, vem produzindo um "Diritto senza verità", como proclama Opocher. Despojado de sentido ético, pompeando inatacável tegumento de digressões silogísticas, o Direito se desenvencilha dos valôres que norteiam o operar humano; em seu nome espalha-se o flagelo da guerra e da hecatombe, aniquilam-se as liberdades e amordaça-se a palavra. Não se correm de exibir as insígnias da Justiça os prègadores do racismo, do destino manifesto de uma nação, os arautos de sociedades angelicais pelo milagre da tirania.

Quantos pseudo-juristas se postram aos pés do poder, numa suposta defesa da autoridade! Desejos de facínoras e dementes adquirem, de imediato, revérbero jurídico, a insinuar que a nossa Ciência é insuscetível de gravitação em tôrno de verdades próprias e de "constantes estimativas".

Implanta-se, assim, no domínio do Direito a concepção atomista e bélica do social, através de uma gama de arbjtrariedades jurisfeitas, que nascem com a hegemonia sem contraste de alguns grupos na ordem interna e culminam com o desvario dos potentados na ordem internacional.

Urge que o Direito se coadune com o renascimento humanista anelado pela nossa época, sob pena de se fossi= lizar como estrutura inerte. Incumbe-lhe, primacialmente, 
projetar a liberdade no dintôrno do espírito comunitário, mediante justo equilíbrio entre o rigor técnico-formal e as solicitações dos valores que o imantam.

0 progresso jurídico, como o da História em geral, não se confunde com a mística econômica, com a acumulação de haveres, porque não se resolve no proliferar estouvado de leis e faculdades de Direito; a sua essência é a marcha para a perfeição do ser, regorgitando-lhe no bôjo, crises, perdas irreversíveis, dilacerações e retornos.

Insta assentar definitivamente: a norma jurídica não é fruto exclusivo de uma técnica, porque antes espelha uma opção radical, delimitada pelos imperativos do humanismo autêntico. A obra legislativa tanto quanto a judiciária não se automatiza, pois reclama embasamento vivo nas consciências.

Não sejam os cultores do Direito camaleões cujas rugosidades sempre têm a côr dos poderosos! Não seja a Jurisprudência o sêlo branco que pretende dignificar o neutralismo dos fins ou a proteção sofisticada das vantagens de alguns! A nossa verdade é a da natureza humana, encarada nos seus aspectos plenários. Defendê-la - consoante a lição de Ihering -- é declarar guerra a miriades de interêsses e arrancar pólipos presos por mil braços.

Duas planícies habita o Direito - pondera Jemolo como em dois cenários se espraiam os adereços do firmamento. Ao céu das estrêlas, com o seu perpétuo esfuzilar corresponde o da Justiça, o dos sumos princípios do bem e do mal, onde as leis haurem as inspirações primeiras. Mais abaixo, está o painel onde o dilúculo se acereja e o pudor da tarde se desenha, onde o corisco faulha sôbre o fundo caliginoso da treva: é a abóbada das regras jurídicas.

A magna contradição do Direito coevo é o olvido dos sumos princípios, enleando-se nas brumas do formalismo.

A diretriz que sempre matizou a História desta Casa foi a síntese entre os dois referidos páramos. Amaldicoam os iconoclastas a poesia nas Arcadas, ferreteiam a 
oratória e satirizam a Filosofia. Os ensinamentos do passado encarregam-se de desmenti-los: o negro não foi redimido por milagre da técnica jurídica, porque a sua salvacão brotou da poesia condoreira de Castro Alves, do verbo candente de Patrocínio, Nabuco e Luz Gama, a desvendar, sôb a epiderme côr de noite dos escravos, majestade equivalente à dos árias; inflamou-se o país, na inolvidável campanha civilista, pela palavra mágica de Ruy; demos à nação uma Carta Magna pelo apostolado dos nossos tribunos.

Devido à ausência de eriçamento emocional, do lume do saber positivo não prorrompeu, como esperava Comte, um "Deus sintético para unir a humanidade" O homem não é apenas um portador de razão, é também o centro da "iluminatio" agostiniana, caminho único para certas verdades. E o Direito - - autêntica dimensão humana -não poderá alçar-se em elevados vôos, sem ter no vértice do seu progresso as idéias-fôrças que acaloram a afetividade.

\section{Humanismo e a problemálica nacionalista}

Ao deixarmos a Academia - verdadeiro bêrço do sentimento nacional, "Ministério Público da História Brasileira" - é mister recordemos que não nos cabe exclusivamente cultivar o Direito puro. Partilha-se entre todos e, de modo especial, entre os membros das jovens gerações, o dever impreterivel de edificar a pujança brasileira.

f forçoso reconhecer: se objetivamente constituimos uma nação, subjetivamente ainda não o somos. Não bastam para formá-la os laços extrínsecos a justapor os seus componentes: só os projetos de vida comum lhe emprestam continuidade no tempo e lhe atribuem fisionomia própria. A simples vontade política gera Estados mas nào plasma Nações.

Assistimos a numerosas rebeldias de casernas, não se operando, contudo, até hoje, a grande revolução nacional, que não é o entrecruzar de projéteis mas deve ser o apare- 
cimento de uma idéia-fôrça, integradora da comunidade brasileira.

Cifra-se a nossa evolução política na coexistência de dois polos que, recìprocamente, se ignoram, por vêzes se tacteiam e jamais se conciliam: um Estado, de tipo cartorial, em antítese com o privatismo egótico.

Vivemos de ensaios e reformas - lamentava insigne sociólogo patrício - cada idéia nova pousa sôbre ruinas; cada transformação planta as aspirações de um sistema sôbre a agreste verdade de formas sociais ainda grosseiras. Daí o desânimo e a descrença de um povo, para quem a vida pública não é senão uma crônica de anedotas pessoais e de audácias..."

Não se estruturou o nosso Estado segundo os ditames de um ideal de cultura, porque a sua regra é a política de clientela. Nenhuma ideologia preside a elaboração das suas leis e constituições, que se sucedem em ritmo frenético, sem qualquer unidade sistemática. Os órgãos do poder exaurem-se no esfôrço de auto-manutenção, sem se enlaçarem ao corpo nacional, para projetá-lo na ascese do progresso. Ante os cidadãos, o Estado se afigura descomunal cartório, onde se venera a forma pela forma. 0 emaranhado processo dos expedientes burocráticos cresta os derradeiros laivos da capacidade construtora dos homens e ao cabo de cada quinquênio, novos programas nulificam o passado, novas experiências emergem e não resta uma instituição nacional, assente sôbre bases próprias, para um crescimento evolutivo.

À margem dos quadros estatais medra o privatismo egótico, transluzindo - consoante a justa crítica de Bilac - a falta de uma corrente de solidariedade de alma para alma, de uma crença comum e de um entusiasmo que congregue todo o povo na mesma aspiração.

Esboça-se agora, ainda pouco difuso, o movimento nacionalista. À nossa geração compete interseri-lo nas coordenadas do novo humanismo que desponta. Assim sendo, o seu primeiro característico deverá repousar no 
"espírito atuante". Urge suprimir o velho hiato entre a vida e a razão; as nossas escolas e as nossas universidades já não podem ser o simples ninho dos louvores ao passado, do bacharelismo vazio e enfim de uma cultura estéril e servil.

O nacionalismo só se concebe como ideologia global de desenvolvimento; reduzi-lo à discriminação arbitrária de meios, segundo critério xenofóbicos, é emprêsa suicida, é zelotismo peculiar aos complexos coloniais, tendentes a erigir a sua condição em ideologia. Se a mira é o engrandecimento nacional, adotem-se as medidas adequadas, julgando-as de acôrdo com os fins colimados e não com preconceitos irracionais.

Não se deturpe a nobreza dessa atitude da consciência histórica brasileira, relegando-a à posição de instrumento grupalista. E da natureza do nacionalismo a referibilidade a tôdas as classes e o predomínio, no seio destas, dos setôres dinâmicos e produtivos. Não frustre, porém, a alucinação da campanha o desiderato comunitário dos povos e sobretudo o dos latino-americanos, que hão de representar o eixo de uma civilização baseada na primazia dos valores do espírito.

Concretizem-se no Brasil os heroismos da palavra através dos heroismos da ação. Substituam-se os ímpetos desordenados pelos que a vitalidade nacional desperta. Seja a expansão do que já nos pertence por direito o princípio da nossa conduta que, dêsse modo, há de conduzir ao imperialismo nosso dentro das nossas fronteiras.

\section{Peroração}

É chegado o momento de despedir-nos da Academia. No perfil apolíneo das Arcadas - afestoado hoje pelo 25. aniversário da sua incorporação à Universidade de São Paulo - tremebrilham os derradeiros lampejos dos nossos dias de vida acadêmica, prestes a se diluirem nos ancenúbios das recordações, onde as imagens despem o manto 
purpúreo da presença para envergar a túnica furtacor da saudade.

Antes, porém, seja-nos permitido retroceder, por um instante no tempo. Concedei, senhores, que, por um milagre da emotividade, caminhando sôbre o oceano silencioso do passado, cheguemos às águas lustrais em que a existência nos batizou, ao florescer o primeiro dos nossos afetos e genuflexos, depositemos no tabernáculo dos nossos lares a borla que nos coroou a jornada universitária, a beca da sagração para as justas do Direito e o rubi que, no seu chamejar, reproduz os eflúvios ardentes dos corações de nossas famílias, acompanhando-nos, passo a passo, nas adversidades e nos triunfos. A vós, genitores e demais parentes, espôsas e noivas, a vós, que manejais o cinzel da realeza do espírito pertencem as hosanas desta noite.

$\mathrm{E}$ aos professôres desta Casa que, durante cinco anos. através das suas palavras e dos seus exemplos, nos instilaram indefectível amor à Justiça, o tributo do reconhecimento, que é o sinete da mais excelsa dignificação humana. Debruam as vagas a imensa tela das fraldas marítimas, enastram os cúmulos sôbre o cerúleo do firmamento as suas madeixas alvinitentes. Tudo isto, porém, reveste o brilho efêmero da fumaça dourada no horizonte. Vós, entretanto, mestres da Academia, desenhais na pauta eterna do espírito, o hino perene do Direito. Bendita a vossa obra!

Em V. Excia. Snr. Paraninfo, encontramos o primor do jurista aliado ao requinte do mestre, cuja alma de poeta é manancial de infinita dedicação aos discípulos. Nas lides que ora se iniciam, Prof. Ernesto Leme, teremos como paradigma o seu devotamento ao Direito, nas incertezas nacionais o seu ardor cívico e nas relações privadas, o zêlo da sua amizade. Ingressando nesta Casa, quando a memorável campanha de Bilac abrasava a Nação, V. Excia. transfundiu em todos os seus atos, com o mesmo denôdo e empenho do grande parnasiano, os ideais hauridos nos 
bancos acadêmicos. Jurisperito de escol, vate de alta envergadura, professor por irresistível vocação, paulista de suma fidalguia e ilimitado amor à nossa terra. V. Excia., secundando a "Águia de Haia" adornou o Brasil com a áureola da glória, ao representar-nos nas Nações Unidas. Ufana-se a Academia do Largo de São Francisco ao rememorar a sua participação no maior forum do mundo. orgulham-se os seus afilhados e a voz humilde que hoje novamente o saúda como há quatro anos o fêz, ao ensejo do seu retôrno à Faculdade, sente a emoção que dominou todos quantos se dirigiram ao insigne Ruy, depois do famoso conclave da Holanda. Por feliz coincidência, das suas bodas argênteas com o magistério superior, surde o nosso noviciado. Praza ao Onipotente que, completando o jubileu de prata da formatura, se tantas glórias não nos engalanarem quantas merecidamente o exaltam, Snr. Paraninfo, possamos volver à "Alma Mater" da Academia, cônscios de que a nossa fidelidade ao seu lábaro foi tão intensa quanto a de V. Excia., pois "Justitia soror incorrupta fides".

Não quis a Providência que, do júbilo da festa de hoje participasse o Prof. Gabriel de Rezende Filho, patrono da turma. Desaparecido inopinadamente, quando concluiamos o $4 .^{\circ}$ ano, o seu espírito jamais há de fenecer nas Arcadas. Não é a morte um empanar de afeições, é apenas uma transposição de perspectivas. Aquêle que outrora nos falava do alto da cátedra e nas tertúlias acadêmicas, fala-nos agora pelas entreabertas do infinito, com os mesmos arpejos de bondade e com idêntico carinho por esta Casa, que foi o seu segundo lar. Descendente de tradicional estirpe de mestres universitários, consagrou o Prof. Gabriel de Rezende Filho ao magistério os melhores esforços da sua existência. Nunca o seduziu a gloríola dos improvisadores; cada aula refletia meticuloso preparo, nimbado pela fé no Direito, como projeção da solidariedade humana. A sua figura serena não se eclipsa em nossa retina; a opulência do seu coração perpetua-se em nossas almas. 
Duas outras personalidades ao lado do patrono, estendem-nos os braços, partícipes da efusão desta formatura, o Prof. Siqueira Ferreira, o defensor intimorato da liberdade, o jurista com têmpera de político e o Prof. Genésio de Almeida Moura, espírito cintilante e jovial, onde a inteligência disputava a prioridade com a simpatia. sem que uma à outra sobrepujasse. A ambos, que deitaram no escrínio de nossas mentes os germes das maiores grandezas, o preito da saudade e da gratidão.

Para atender a costumeiro ritual, ouçamos as palavras de despedida das três deusas, invisíveis, embora reais, que emanam mágicos influxos sôbre os destinos dêste templo, recebendo-nos quando calouros, estreitando-nos em afetuoso amplexo quando partimos.

Como as três faces do tempo dispõem-se essas vestais: uma é o presente - a Mocidade, outra o passado - a Saudade, a última o futuro - a Esperança.

Fala-nos a princípio a Saudade, delícia dos outonos, ametista em que se transmuda o rubro dos nossos sonhos. E esta nos diz: "Levai convosco o "Espírito da Academia", enaltecendo-o cotidianamente pelas vossas ações. Levai a poesia, levai a eloquência, levai o Direito permeado de liberdade e sentido humano.

E silencia para que fale a Esperança, prelúdio dos feitos memoráveis, embrião que o espírito acalenta e desenvolve por amor à grandeza vocacional e ela nos diz: "Se esta Casa vive também do passado não pode viver só do passado. Sêde os bandeirantes do humanismo para que a técnica, a Política e o Direito não coisifiquem a pessoa concreta, "misto de sangue e de luz". A persuasão e a fé são os soberanos dêste mundo. As conquistas da fôrça bruta em breve se estiolam. Enriquecei o pauperismo tecnocrata com a fecúndia dos valores pelos quais viveis, padeceis e sucumbis. Completai a imensidão do vosso território com a intrepidez de uma alma nacional que possibilite o vosso imperialismo dentro das vossas fronteiras. Dai ao Direito a rutilância de uma verdade, para 
que se não amesquinhe em enfadonha "congérie" de formas. Erguei, por fim, uma cultura que seja o vosso luzeiro e vos proporcione a visão do Tabor que só o pensamento desvenda.

E calando-se a Esperança, aureja afinal a Mocidade, refúgio e fortaleza onde o Eterno dá asilo à glória e ela nos diz: "Sou a corporificação da Esperança, a semente da liberdade, em uma palavra, o enlêvo do mundo. Fitaime e recordareis a História Humana, nas cumiadas do seu fastígio. Inseri-me, por vosso ideal, no borborinho da crise contemporânea e no silêncio da vossa subjetividade e o meu sôpro, roçando a fronte serena da vossa raça, como outrora o fêz nas praias do Arquipélago e sob os olivais da Jônia, há de levantar uma civilização consentânea com a dignidade do homem. O castigo das gerações que pecam contra mim é o próprio aniquilamento.

$\mathrm{E}$ ao ouvirmos a última e a mais radiante das três divindades, nós respondemos, parodiando Bilac:

\author{
Não morrerás, Deusa sublime! \\ Do trono egrégio \\ Assistirás intacta ao crime \\ Do sacrilégio. \\ Vive! que eu viverei servindo \\ Teu culto, e, obscuro, \\ Tuas custódias esculpindo \\ No ouro mais puro.
}

Quando a vida esfalfada e temerosa bater-nos às portas, pedindo uma centelha de Justiça e solidariedade, nós saberemos, em teu nome, ó Mocidade, dar a "charitas sapientis" a que aludia Leibnitz e alçaremos até o infinito a bandeira que nas Arcadas nos legaste, bandeira de luz! bandeira de liberdade! bandeira de redenção! 